\title{
Green Synthesis and Characterization of Silver Nanoparticles of Leaf Extracts of Priva cordifolia (L. F.) Druce
}

\author{
R. Amster Regin Lawrence, T. Leon Stephan Raj ${ }^{*}$, A. Antony Selvi \\ Post Graduate and Research Department of Botany, St. Xavier's College (Autonomous), Palayamkottai, Tirunelveli, Tamil Nadu, India
}

\section{Email address:}

leostephanraj@gmail.com (T. L. S. Raj)

${ }^{*}$ Corresponding author

\section{To cite this article:}

R. Amster Regin Lawrence, T. Leon Stephan Raj, A. Antony Selvi. Green Synthesis and Characterization of Silver Nanoparticles of Leaf Extracts of Priva cordifolia (L. F.) Druce. International Journal of Ecotoxicology and Ecobiology. Vol. 2, No. 1, 2017, pp. 52-55. doi: $10.11648 /$ j.ijee.20170201.17

Received: October 31, 2016; Accepted: February 15, 2017; Published: March 2, 2017

\begin{abstract}
A basic need in the field of nanotechnology is the development of reliable and eco-friendly techniques for synthesis of metal nanoparticles. To accomplish this need the plant system has emerged as an efficient living factory for synthesis of metal nanoparticles. The synthesis of metal nanoparticles using plants is non-toxic, fast, takes place at ambient temperature and low cost. A variety of plants and plant organs (leaf, stem, root and bark) and plant enzymes have shown the successful synthesis of metal nanoparticles. In the present investigation $\mathrm{AgNO}_{3}$ mediated nanoparticles were synthesized using the leaf extracts of Priva cordifolia (L. F.) Druce. belonging to the family Verbenaceae and it was characterized by UV-VIS spectrum, X-Ray Diffraction studies, EDX and SEM analysis. Color change, SEM, EDX and XRD analysis confirmed the stability of synthesized AgNPs. The antimicrobial potential and wide applications of AgNPs in different fields could be analyzed in future.
\end{abstract}

Keywords: Nanoparticles, Priva cordifolia, AgNPs, SEM, XRD

\section{Introduction}

Nanobiotechnology is the recently growing techniques in the scientific world. The nanoparticle was used in different fields of scientific research. It may be synthesized chemically or biologically with living organisms. There is an enormous interest in the synthesis of nanoparticles due to their unusual optical [1], chemical [2], photoelectrochemical [3] and electronic [4] properties. The plant mediated green synthesis of silver nanoparticles plays an important role in medicinal field especially in drug discovery of pharmaceutical industries. Recent studies on the use of plants and microorganisms in the synthesis of nanoparticles are a relatively new and exciting area of research with considerable potential for development. It is well known that many plants can provide inorganic materials either intra- or extracellularly [5] and microorganisms are recently found as possible eco-friendly nano-factories [6, 7]. Physical properties of nanoparticles such as large surface area, energy, spatial confinement and reduced imperfections are the attractive attributes that lay a platform for its application in multiple approaches [8]. Among the various methods like sol-process, micelle, sol-gel process, chemical precipitation, hydrothermal method, pyrolysis, chemical vapor deposition, bio-based protocol etc., bio-based protocol is the most important and eco-friendly production method [9]. Processes devised by the nature for the synthesis of inorganic materials on nano- and microlength scales have contributed to the development of a relatively new and largely unexplored area of research based on the use of microbes in the biosynthesis of nanoparticles [10]. Green synthesis offers improvement over other methods, i.e., synthetic, chemical or using micro-organisms, as it is reported to be cost-effective, environmentally friendly and non-toxic to the environment and can be used for large-scale synthesis [11]. The green chemistry method is based on the mechanism of plant-assisted reduction due to the presence of phytochemicals [12]. The main phytochemicals involved are flavones, aldehydes, terpenoids, ketones, carboxylic acids and amides.

Green synthesis of silver nanopartilce is studied in many plants, but there is no report in silver nitrate mediated leaf synthesized nanoparticles in Priva cordifolia. Priva cordifolia 
belonging to the family Verbenaceae is one of the major groups of Angiosperms (flowering plants). The family Verbenaceae includes 41 genera and 950 species which contains trees, lianas, shrubs and herbs [13]. In herbal medicine, Priva cordifolia used to treat the wounds [14], ulcer and used as anti-fertility factor and treatment for diarrhea [15]. There is also report on its use to treat migraines [16]. Leaf powder of the plant is used to drive away bugs and also act as mosquito repellent and leaf paste for eczema [17]. Based on the medicinal potential of the plant, the present investigation is framed to study the synthesis and characterization of silver nitrate mediated nanoparticles of leaf extracts of Priva cordifolia (L f.) Druce.

\section{Materials and Methods}

The plant material selected for the present study is $P$. cordifolia (L f.) Druce. belonging to the family Verbenaceae. The plant material was collected from the campus of St. Xavier's College (Autonomous), Palayamkottai, Tamil Nadu, India and identified with the help of herbarium specimen deposited in St. Xavier's College herbarium (XCH).

\subsection{Preparation of the Fresh Leaf Extract for Nano Particle Isolation}

In a conical flask, $10 \mathrm{~g}$ of fresh leaf was boiled with $100 \mathrm{ml}$ of bi-distilled water. The extraction was filtered through what's Mann no.1 filter paper. The filtered samples were collected in a conical flask. The obtained extract was used for the synthesis of silver nanoparticles.

\subsection{Preparation of Silver Nitrate Solution}

$1 \mathrm{mM}$ silver nitrate solution was prepared by the concentration of $0.0169 \mathrm{gm}$ in $100 \mathrm{ml}$ bi-distilled water and stored.

\subsection{Metal-Plant Extracts Interaction}

In conical flask, $90 \mathrm{ml}$ of the silver nitrate solution was added to $10 \mathrm{ml}$ of the plant leaf extract. The color change of silver nitrate solution was found from colorless to dark brown. The conical flask was incubated at light for 72 hours.

\subsection{UV-visible Spectra Analysis of Silver Nanoparticles}

The bio reduction of reaction mixture of pure silver ions was absorbed by observing the UV-visible spectrum at different time intervals taking $1 \mathrm{ml}$ of the sample, compared with $1 \mathrm{ml}$ of $1 \mathrm{~mm} \mathrm{Ag} \mathrm{NO}_{3}$ used as blank. UV-visible spectral analysis has been one by using Shimadzu UV- Visible spectrophotometer at a resolution of $1 \mathrm{~mm}$ from $200-800 \mathrm{~nm}$ [18].

\subsection{XRD Analysis of Silver Nanoparticles}

The characterization of purified synthesized silver nanoparticles were freeze dried powered and used for XRD analysis (XRD, model name) at $40 \mathrm{kv} / 20 \mathrm{~mA}$ using continuous scanning 2 delta mode [19]. The silver nanoparticles solution was purified by repeated centrifuged at $5000 \mathrm{rpm}$ for 20 minute followed by redispersion of the pellet of silver nanoparticles into $10 \mathrm{ml}$ of deionized water.

\subsection{SEM and EDX Analysis of Silver Nanoparticles}

Energy dispersive X-ray spectrometers take advantage of the photon nature of light. In the X-ray range the energy of a single photon is just sufficient to produce a measurable voltage pulse X-ray, the output of an ultra low noise preamplifier connected to the low noise are a statistical measure of the corresponding quantum energy. By digitally recording and counting a great number of such pulses with in a so called Multi Channel Analyzer, a complete image of the $\mathrm{X}$-ray spectrum is building up almost simultaneously. This digital quantum counting technique makes the energy dispersive spectrometry exceedingly reliable. A semiconductor material is used to detect the $\mathrm{x}$-rays together with processing electronics to analyses the spectrum.

SEM analysis was done using VEGA3 TESCAN machine. Thin films of the sample were prepared on a carbon coated copper grid by just dropping a very small amount of the sample on the grid, extra solution was removed using a blotting paper and then the film on the SEM grid were allowed to dry by putting it under a mercury lamp for $5 \mathrm{~min}$.

\section{Result and Discussion}

\subsection{UV-visible Spectrum Analysis}

The addition of aqueous leaf extract of $P$. cordifolia into $1 \mathrm{mM}$ silver nitrate solution led to the appearance of a yellow brown color solution after 10 minutes indicating the formation of Ag nanoparticles. A visible color change from transparent to yellow with in $15 \mathrm{~min}$ indicates the formation of silver nanoparticles which was confirmed by UV-visible spectroscopy. Further the color change to dark orange-brown is due to increase the concentration, as well as growth of silver nanoparticles. After few minutes there was no significant color change, which is evidence for the completion of reduction reaction.

\subsection{X-ray Diffraction Studies}

The biosynthesized silver nanoparticle by employing $P$. cordifolia leaf extract was further demonstrated and confirmed by the characteristic peaks observed in XRD analysis. Analysis through X-ray diffraction was carried out to confirm the crystalline nature of the silver nanoparticles. A comparison of our XRD spectrum with the standard confirmed that the silver particles formed in our experiments were in the form of nanocrystals (Figure 1), as evidenced by the peaks at $2 \theta$ values of $27.80^{\circ}, 32.19^{\circ}$ and $46.15^{\circ}$ corresponding to the height of (37.01), (75.81) and (27.29), respectively. The corresponding 'd' spacing value of Ag nanoparticles were 3.21, 2.78, and 1.97 The silver nanoparticles exhibit yellow brownish color in aqueous solution due to excitation of surface Plasmon vibrations in silver nanoparticles [20]. 


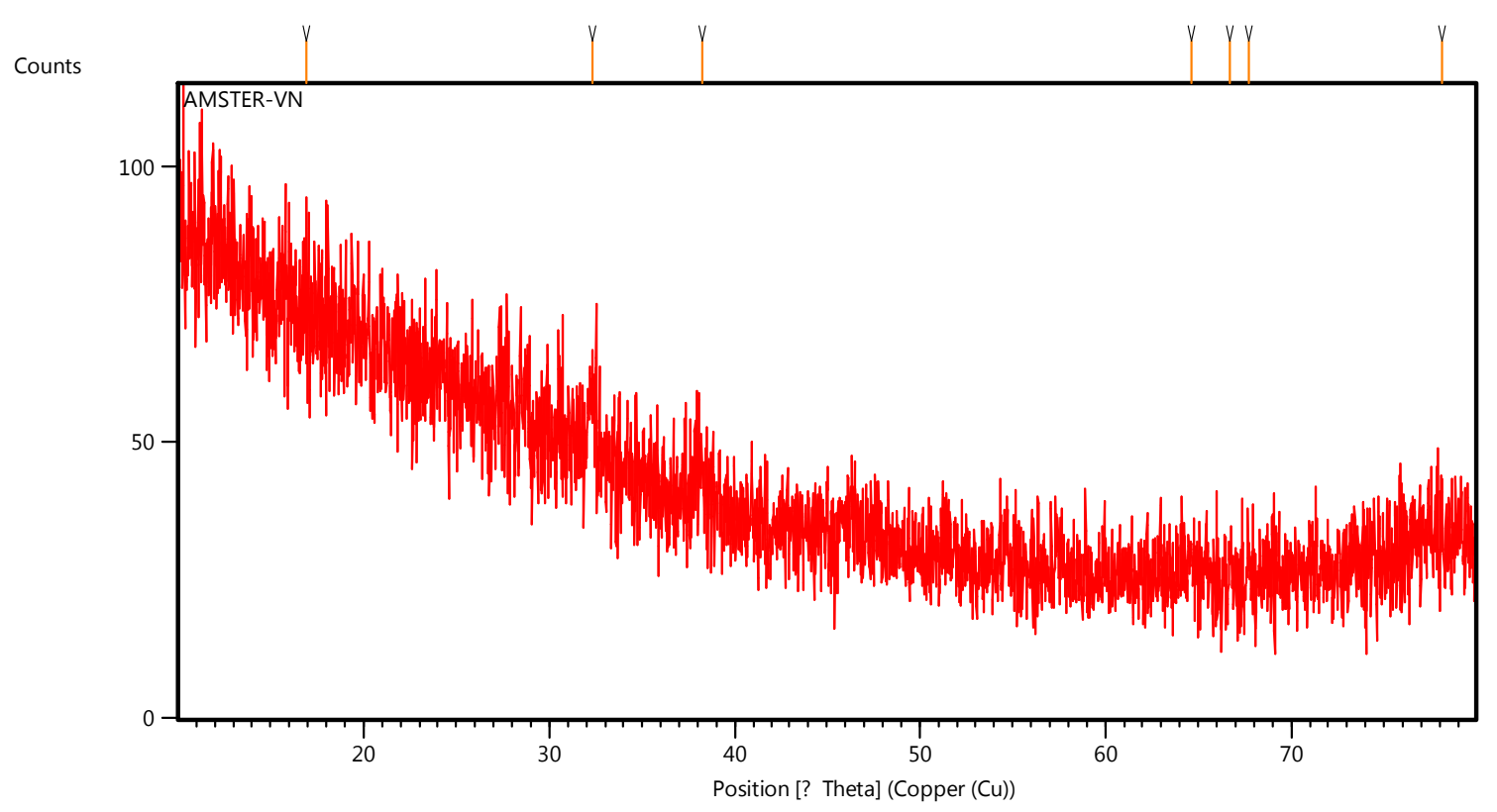

Figure 1. XRD Pattern of SNPS Synthesized by Priva cordifolia Leaf Extract with $\mathrm{AgNO}_{3}$ Solution.

\subsection{EDX Analysis of Silver Nanoparticles}

EDX analysis gives qualitative, as well as quantitative status of elements that may be involved in formation of nanoparticles. In this study, EDX was used to verify the presence of silver in the suspension of nanoparticles purified by ultracentrifugation. The EDX result showed a small peak of silver that confirmed its presence in the suspension (Figure 2). The amount (percentage) of elements present in the suspension is shown in the Table 1.
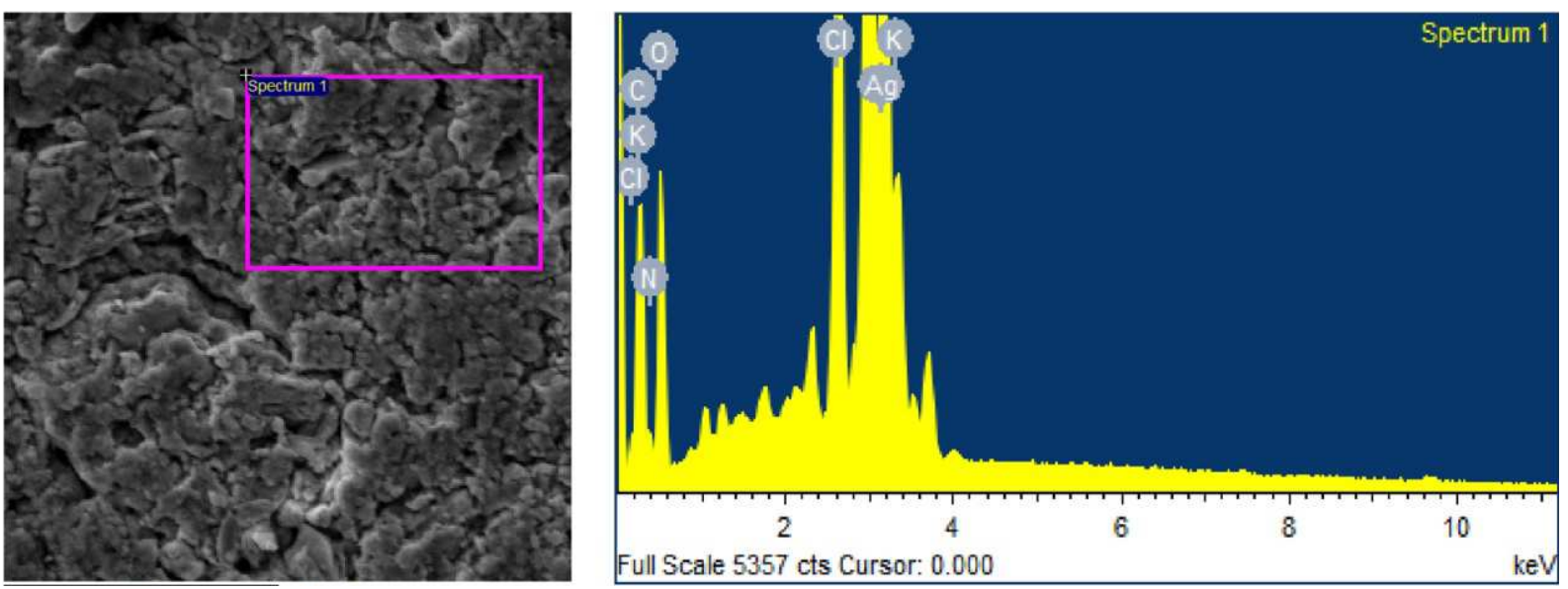

Figure 2. EDX analysis of SNPS Synthesized by Priva ccordifolia Leaf Extract with $\mathrm{AgNO}_{3}$ Solution.

Table 1. EDX curve with five dominant peaks for $\mathrm{C}, \mathrm{O}, \mathrm{K}, \mathrm{N}, \mathrm{Cl}$ and $\mathrm{Ag}$ respectively.

\begin{tabular}{lll}
\hline Elements & Weight\% & Atomic\% \\
\hline $\mathrm{C} \mathrm{K}$ & 13.39 & 28.13 \\
$\mathrm{~N} \mathrm{~K}$ & 9.15 & 16.47 \\
$\mathrm{O} \mathrm{K}$ & 25.54 & 40.26 \\
$\mathrm{Cl} \mathrm{K}$ & 5.32 & 3.78 \\
$\mathrm{~K} \mathrm{~K}$ & 1.12 & 0.72 \\
$\mathrm{Ag} \mathrm{L}$ & 45.48 & 10.64 \\
Total & 100.00 & 100.00 \\
\hline
\end{tabular}

\subsection{SEM Analysis of Silver Nanoparticles}

The analysis of the scanning electron microscopy (SEM) images predicts the formation and the morphology of stable silver nanoparticles obtained from the leaf extract of $P$. cordifolia. SEM analysis shows uniformly distributed silver nanoparticles on the surfaces of the cells (Figure 3 ). The silver nanoparticles were spherical in shape with particle size range from 2 to $20 \mu \mathrm{m}$. The larger silver particles may be due to the aggregation of the smaller ones, due to the SEM measurements. 

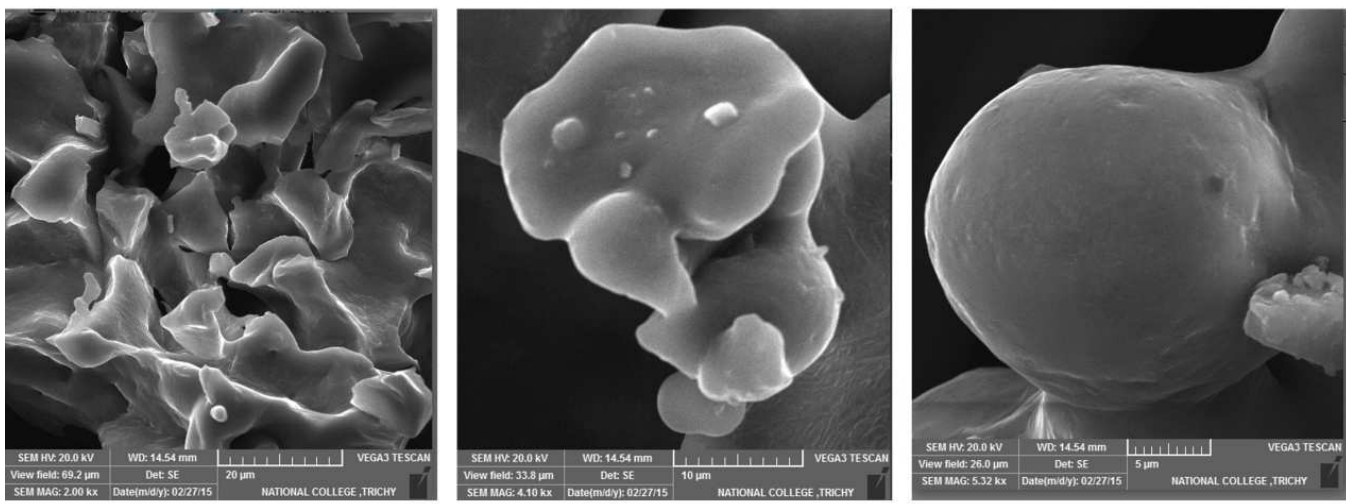

Figure 3. SEM image of SNPs Synthesized by Priva cordifolia Leaf Extract with $\mathrm{AgNO}_{3}$ Solution.

\subsection{Conclusion}

The nanoscale understanding of the bioprocesses and interventions are only in infancy. The areas particularly bioprocess product exploitations are only in current focus that in itself has opened vistas in a technology upsurge. The order beneath the chaos at the genomic level is recognizable but not yet been fully understood. Among the different methods for NP synthesis, the chemical reduction method and green synthesis method were widely studied due to their advantage in controlling particle size and morphology. The antimicrobial potential and wide applications of AgNPs in different fields could be analysed in future.

\section{Acknowledgement}

The authors are greatly acknowledged the constant support and encouragement of management of St. Xavier's College (Autonomous), Palayamkottai.

\section{References}

[1] Krolikowska, A., Kudelski, A., Michota, A., Bukowska, J. SERS studies on the structure of thioglycolic acid monolayers on silver and gold. Surf Sci. 2003, 532, 227-232.

[2] Kumar, A., Mandal, S., Selvakannan, P. R., Parischa, R., Mandale, A. B., Sastry, M. Investigation into the interaction between surface-bound alkylamines and gold nanoparticles. Langmuir. 2003, 19, 6277-6282.

[3] Chandrasekharan, N., Kamat, P. V. Improving the photoelectrochemical performance of nanostructured $\mathrm{TiO} 2$ films by adsorption of gold nanoparticles. J Phys Chem. 2000, B 104, 10851-10857.

[4] Peto, G., Molnar, G. L., Paszti, Z., Geszti, O., Beck, A., Guczi, L. Electronic structure of gold nanoparticles deposited on SiOx/Si(100). Mater Sci Eng C. 2002, 19, 95-99.

[5] Mann, S. Molecular tectonics in biomineralization and biomimetic materials chemistry. Nature. 1993, 365, 499-505.

[6] Southam, G., Beveridge, T. J. The in vitro formation of placer gold by bacteria. Geochim Cosmochim Acta. 1994, 58, $4527-4530$.
[7] Beveridge, T. J., Murray, R. G. E. Site of metal deposition in the cell wall of Bacillus subtilis. J Bacteriol. 1980, 141, 876887.

[8] Morons, J. R., Elechiguerra, J. L., Camacho, A., Holt, K., Kouri, J. B., Ramirez, J. T., Yacama, J. M. The bactericidal effect of silver nanoparticles. Nanotechnology. 2005, 16, 2346-2353.

[9] Leela, A., and Vivekanandan, M. Tapping the unexploited plant resources for the synthesis of silver nanoparticles. African Journal of Biotechnology. 2008, 7 (17), 3162-3165.

[10] Sastry, M., A. Ahmad, M. I. Khan, R. Kumar. Biosynthesis of metal nanoparticles using fungi and actinomycete. Curr. Sci., 2003, 85, 162-170.

[11] Ghorbani H. R., Safekordi, A. A., Attar, H., Rezayat Sorkhabad, S. M. (Biological and non-biological methods for silver nanoparticles synthesis. $J$ Chem Eng Sci and Res Branch. 2011a, 25 (3), 317-326.

[12] Pavani, K. V., Sunilkumar, N., Grayathramma, K. Plants as ecofriendly nanofactories. J Biosci. 2012, 6 (1), 1-6.

[13] Mabbereley, D. The plant -Book, 2nd Ed. Cambridge University press, Cambridge, Gt. Britain. 1997.

[14] Ayyanar, M. and Ignacimuthu, S. "Herbal medicines for wound healing among tribal people in Southern India: Ethnobotanical and Scientific evidences". International Journal of Applied Research in Natural Products. 2009, 2 (3), 29-42.

[15] https://www. giz. de/expertise/downloads/giz2014-en-aids. pdf

[16] opendata. keystone-foundation. org/priva-cordifolia-1-f-druce

[17] Ganesan, S., Venkateshan, G. and Banumathy, N. (). " Medicinal plants used by ethnic group Thottianaickans of Semmalai hills (reserved forest), Tiruchirapalli district, Tamil Nadu". Indian Journal of Traditional Knowledge. 2006, 5 (2), 245-252.

[18] Ankamwar, B., Damble, Basra, C. Biosynthesis of gold and silvernanoparticles using Emblicaofficinalis fruit extract. $J$ Nanosci Nanotechno. 2005, 10, 1665-71.

[19] Absar, A., Shankar, S., Murali, S. Geranium leaf biosynthesis of silver nanoparticles. Biotechnology prong. 2003, 19, 162731 .

[20] Mulvaney, P. Surface plasmon spectroscopy of nanosized metal particles. Langmuir. 1996, 12, 788. 